\title{
Atentados en Paris 2015: entre la dramaturgia televisiva y la indignación de las redes sociales de Internet ${ }^{*}$
}

\author{
Attacks in Paris, 2015: \\ between TV drama and outrage of Internet social networks \\ Atentados em Paris no ano 2015: \\ entre a dramaturgia televisiva e a indignação das redes sociais
}

Recibido el 1 de septiembre de 2016. Aceptado el 17 de noviembre de 2016

\begin{abstract}
Andrés Fernando Orozco Macías**
Colombia
\end{abstract}

- Para citar este artículo:

Orozco Macías, Andrés

Fernando (diciembre, 2016) Atentados en París 2015: entre

la dramaturgia televisiva y la indignación de las redes sociales de Internet. Ánfora, 23(41), 157-

178. Universidad Autónoma de Manizales. ISSN 0121-6538.

\section{Resumen}

Objetivos: comprender el mensaje de los telenoticieros en contraste con las expresiones emotivas y valorativas de las redes sociales, a partir de los atentados terroristas de 2015 en París. Metodología: investigación cualitativa con análisis comparativo y de contenido que sirvió para entender, mediante contraste, los procesos expresivos de los telenoticieros comparados con los procesos valorativos y emotivos de los usuarios de las redes sociales, en relación con los atentados terroristas de París en 2015. Se recolectó la información de dos páginas de Facebook. Luego, se contrastó el valor dramático de los

\footnotetext{
* El artículo es producto de la investigación "Emociones y espectáculo políticos en Facebook" adscrito al grupo de investigación: "Historia, trabajo, sociedad y cultura" A1 en Colciencias, desarrollado en la línea: "Historia Virtual y Laboratorio de Fuentes Audiovisuales", para optar al título de Magister en Estudios Políticos de la Universidad Nacional de Colombia sede Medellín. La investigación se inició en Febrero de 2015 y fue sustentada y aprobada en 17 abril de 2016.

** Magister en Estudios Políticos. Profesor de la Universidad Nacional de Colombia, sede Medellín. Correo electrónico: aforozcom@unal.edu.co - andresorozco08@gmail.com
} 
telenoticieros frente a los atentados en París con las emociones y valoraciones de los usuarios de las redes frente al mismo acontecimiento. Resultados: se evidenció que los telenoticieros unifican la emisión del mensaje y no diversifican las expresiones sobre el mismo, a diferencia de las redes sociales que están cargadas de múltiples expresiones emocionales frente a un acontecimiento. El contraste generó comprensión sobre otras visiones políticas de Francia en las que no aparece como víctima del atentado, sino la causante del mismo. Conclusiones: se concluye que las redes sociales están cambiando las formas de participación política. La televisión ya no impone una interpretación global de los acontecimientos. Internet da voz a los actores informales de la política que abren nuevos focos de interpretación y participación a través de formas valorativas y emotivas de la política.

Palabras claves: Telenoticieros vs Redes Sociales, Política, Emotividades

\section{Abstract}

Objective: to understand the message of the TV news in contrast to the emotional and value expressions in the social networks about the terrorist attacks in Paris, 2015. Methodology: a qualitative research that comprises a comparative and content analysis helping to understand, by contrast, expressive processes of the TV news compared to evaluative and emotional processes of social network users in regard to the terrorist attacks in Paris, 2015. Information from two Facebook pages was collected. The dramatic value of the TV news which covered the attacks in Paris was contrasted with the emotions and user ratings of networks with respect to the same event. Results: they showed that TV news standardizes broadcast of the message and does not diversify its expressions, unlike the social networks which are loaded with diverse emotional expressions against an event. The contrast generated an understanding of other political perceptions of France in which it does not appear as a victim of the attack but as a cause. Conclusions: it is concluded that social networks are changing how people participate politically. Television no longer imposes a comprehensive interpretation of events. Internet gives voice to informal political actors that open up new sources of interpretation and participation through value and emotional ways of politics.

Keywords: Social Networks vs. TV news, Politics, Emotions 


\section{Resumo}

Objetivos: compreender a mensagem dos noticiários em contraste com as expressões emocionais e valorativas das redes sociais, a partir dos ataques terroristas de 2015 em Paris. Metodologia: pesquisa qualitativa com análise comparativa e de conteúdo que serviu para entender, mediante contrastes os processos expressivos dos noticiários em comparação com os processos valorativos e emocionais dos usuários de redes sociais, em conexão com os ataques terroristas em Paris, no ano 2015. A informação foi recolhida de duas páginas de Facebook. Em seguida, o valor dramático dos noticiários frente aos atentados em Paris foi contrastado com as emoções e valorizações dos usuários das redes sociais em referencia com o mesmo evento. Resultados: evidenciou-se que os noticiários unificam a emissão da mensagem e não diversificam as expressões, ao contrário das redes sociais que estão carregadas com várias expressões emocionais sobre um evento. $\bigcirc$ contraste gerou entendimento sobre outras visões políticas da França nas quais ela não aparece como uma vítima do ataque, senão como a causante do mesmo. Conclusões: conclui-se que as redes sociais estão mudando as formas de participação política. A televisão já não impõe uma interpretação global dos acontecimentos. A internet dá voz aos atores informais da política os quais abrem novos focos de interpretação e participação através de formas valorativas e emocionais da política.

Palavras-chave: Redes Sociais vs Noticiários, Política, Emotividades 


\section{Introducción}

Después de la Investigación "Emociones y espectáculo político en Facebook: dramaturgia política en la campaña presidencial de 2014" se dedujo la importancia de las emociones y expresiones políticas de los usuarios en las redes sociales. La investigación sostiene que las redes sociales son el escenario propicio para la participación y expresión emotiva de los ciudadanos frente a los acontecimientos sociales, culturales o políticos (Orozco, 2016). Tales expresiones se dan en un proceso de transición entre un objeto monovalente como la televisión hacia uno interactivo como Internet, como lo define claramente Sartori (1998):

Cuando hace apenas cincuenta años de su aparición, la televisión ya ha sido declarada obsoleta. Las nuevas fronteras son Internet y el ciberespacio, y el nuevo lema es «ser digitales». El salto es grande y la diferencia es ésta: que el televisor es un instrumento monovalente que recibe imágenes con un espectador pasivo que lo mira, mientras que el mundo multimedia es un mundo interactivo (y, por tanto, de usuarios activos) y polivalente (de múltiple utilización) cuya máquina es un ordenador que recibe y transmite mensajes digitalizados (p. 53).

Tras la clara diferencia conceptual que establece Sartori (1998) en la función técnica y mediática de ambos medios, es pertinente cuestionar ¿Cómo confrontan las redes sociales el mensaje monovalente de los telenoticieros mediante la expresión de múltiples formas políticas y sociales sobre los acontecimientos en París en noviembre de 2015? La pregunta lleva a un análisis comparativo y de contenido en las imágenes y mensajes emitidos por televisión y las redes sociales; con ello, se busca puede comprender de modo conciso la multiplicidad de percepciones políticas emitidas a través de las redes sociales frente a un acontecimiento de carácter global.

En el desarrollo teórico para sostener el análisis del contenido fue necesario abordar los conceptos de emociones y valores políticos de la teoría de Manuel Castells. Éstos, ilustran de manera clara el proceder emotivo de las percepciones políticas respecto a acontecimientos de impacto a mundial; tales conceptos también permiten entender el valor político de los actores informales que encuentran en internet la oportunidad para contextualizar sus percepciones sobre acontecimientos tratados por la televisión desde una perspectiva "políticamente correcta", que favorece poderes políticos con alcance global. El autor mencionado permite una comprensión de la función emocional de las redes y cómo estas 
cumplen el papel de organizar estas emociones en comunidades digitales que se distribuyen en la red.

El artículo pretende mostrar, mediante el contraste y el análisis comparativo, que la televisión no permitió un intercambio informativo entre el televidente y la producción audiovisual del mensaje con respecto a la emisión del acontecimiento en París durante noviembre de 2015. Esto se debió a que la televisión no logró agrupar las percepciones políticas del sujeto, ni abrió alternativas a que los televidentes fueran actores activos de la producción audiovisual; la contraparte es que internet es estructuralmente incluyente y abierto a la múltiple participación emocional y valorativa de los acontecimientos.

Finalmente, la investigación genera perspectivas de análisis frente a acontecimientos mundiales con alto contenido político, ya las redes de internet dan voz a los actores políticos informales donde no hay libretos mediatizados como en los telenoticieros, sino, la emoción política y el valor que el sujeto le da a partir de la red social que habita y que permite en tiempo real expresar lo que sienten y lo que piensan.

\section{Metodología}

Esta investigación de corte cualitativa hizo un análisis comparativo entre los procesos dramáticos de las emisiones televisivas de los noticieros y la reacción de algunos usuarios en páginas de Facebook, con una posición crítica frente a las acciones militares de Francia en otros países.

Los telenoticieros analizados coinciden en etiquetar el acontecimiento bajo la conceptualización de terrorismo sin previos análisis de los posibles ataques; más bien, recurrieron a narrar la evolución de acontecimientos y de cifras bajo un aspecto dramático con palabras como un "espectáculo de terror" o "identificarse con el dolor" y no las posibles incidencias y los antecedentes militares de Francia hacia otros países.

Con lo anterior, se hizo un contraste con la reacción de algunas páginas y usuarios de dos páginas de Facebook para distinguir la información emitida por estos telenoticieros y las opiniones críticas como fuente de análisis de valor y emotivas de la forma de participación activa que los usuarios tienen en la red. 
Para el análisis de contenido de los atentados de París por el Estado Islámico (ISIS) el 13 de noviembre de 2015, se tomaron destacados noticieros con una amplia difusión global como CNN, Fox News y Canal 13 de España. En estos medios se narrarraron, minuto a minuto, los sucesos a manera de guía informativa y explicativa para millones televidentes. Igualmente, el análisis de contenido también fue aplicado a dos páginas de Facebook: "Colectivo Dignidad" "Anti-Illuminati 503" que reflejan una posición valorativa con una perspectiva política, a partir de las imágenes y mensajes emitidos por los miembros y administradores de las páginas.

Los mensajes emitidos por los noticieros mencionados anteriormente, permiten encasillar el desarrollo noticioso bajo los conceptos de dramaturgia y representación, donde no se expone la diversidad de valores u opiniones sobre otros acontecimientos con la misma cantidad de víctimas; por consiguiente, el contraste se da con una serie de imágenes que se postean en las redes sociales de los perfiles de Facebook analizados y mencionados anteriormente.

Con estas páginas analizadas, en un primer momento se tomaron las reacciones de los acontecimientos en París, a través de las imágenes que criticaron la amplia difusión y la "ceguedad" de los telenoticieros que no establecieron antecedentes de los ataques. La segunda página nos permitió entender la mirada que tienen algunos usuarios acerca de la televisión como un medio incompleto e inocuo a la hora de adquirir información de orden político diverso.

El análisis comparativo se desarrolla en la misma línea del análisis de contenido; el uno no difiere el otro, sino que lo complementa; cada una de las imágenes expuestas de los ejemplos televisivos y de las páginas de Facebook, identifican cambios cualitativos en la forma en que los sujetos se comunican y que está generando nuevas sociedades de conexión global con un ámbito evidentemente virtual. Ello demuestra de manera concisa que la televisión no representa la totalidad de las emociones de sus televidentes, que hoy en día los usuarios en las redes de internet son productores activos de información a partir de sus vivencias y de sus percepciones sobre lo que produce la televisión y los telenoticieros, son emisores de emociones e información con un alcance global.

\footnotetext{
1 Página: Colectivo Dignidad, enlace: https://www.facebook.com/COLECTIVODIGNIDAD.ORG/?fref=ts 2 Página: Anti-Illuminati 503, enlace: https://www.facebook.com/Antillluminati503/?fref=ts
} 


\section{Resultados}

En el desarrollo de la investigación se establecieron tres momentos en los resultados: Telenoticieros unificando la indignación, Redes sociales sientan posiciones frente a los atentados en París y Usuarios en Facebook y su percepción de la televisión.

El primero, analizó los telenoticieros con el fin de revelar la unificación del mensaje tras los acontecimientos puestos en evidencia: Al dar muestra de lo anterior, tras tres ejemplos televisivos seleccionados, se dio paso al contraste en el mensaje producido por las redes, a partir de dos páginas de Facebook y la interacción de sus miembros; esto permitió mostrar la diversidad de emociones y valoraciones políticas con respecto a un acontecimiento de carácter global.

Por el esquema anterior, en este apartado se muestran los resultados de la investigación con base en los siguientes tópicos: la unificación de la indignación de los noticieros, la percepción de la T.V según los usuarios de Facebook y las posiciones que adoptan los usuarios de las redes sociales frente a los atentados en París.

\section{Telenoticieros unificando la indignación}

En la noche del 13 de noviembre de 2015, hubo una serie de ataques militares en París, que incluyó dos tiroteos: uno en un teatro y otro en un restaurante, varias explosiones, entre ellas, la de Brasserie cerca del estadio de París. Esto dejó 132 muertos y 352 heridos, según la BBC de Londres (BBC, 2015). La autoría se la adjudicó la denominada organización terrorista Estado Islámico (ISIS).

Como todo acontecimiento en una capital europea, los noticieros no se hicieron esperar; entre ellos canal 13 de Televisión de España, la CNN y Fox News hicieron transmisiones continúas de 4 y 5 horas, develando cada detalle del acontecimiento. Los tres noticieros televisivos puestos en el análisis agruparon el acontecimiento bajo el mismo concepto de terrorismo: dieron forma a una misma realidad cultural y política de sus televidentes, haciendo una misma interpretación y generando un mismo mensaje emotivo, resaltando el localismo parisino, dando fuerza a la idea de una Aldea Global(McLuhan, 1995). 
Imagen 1. Análisis político "El Cascabel" del canal 13 TV durante los atentados

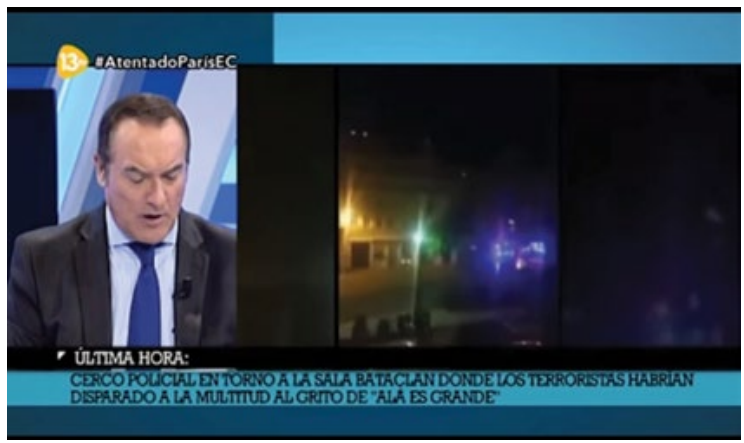

Presentador del Canal 13 de España narrando los acontecimientos en tiempo real sobre París, mencionando el episodio como un verdadero espectáculo de terror.

Fuente: recuperado de YouTube: youtube.com/watch?v=pmj5VdeLSZA

Imagen 2. CNN noticiero en vivo tras los atentados en París

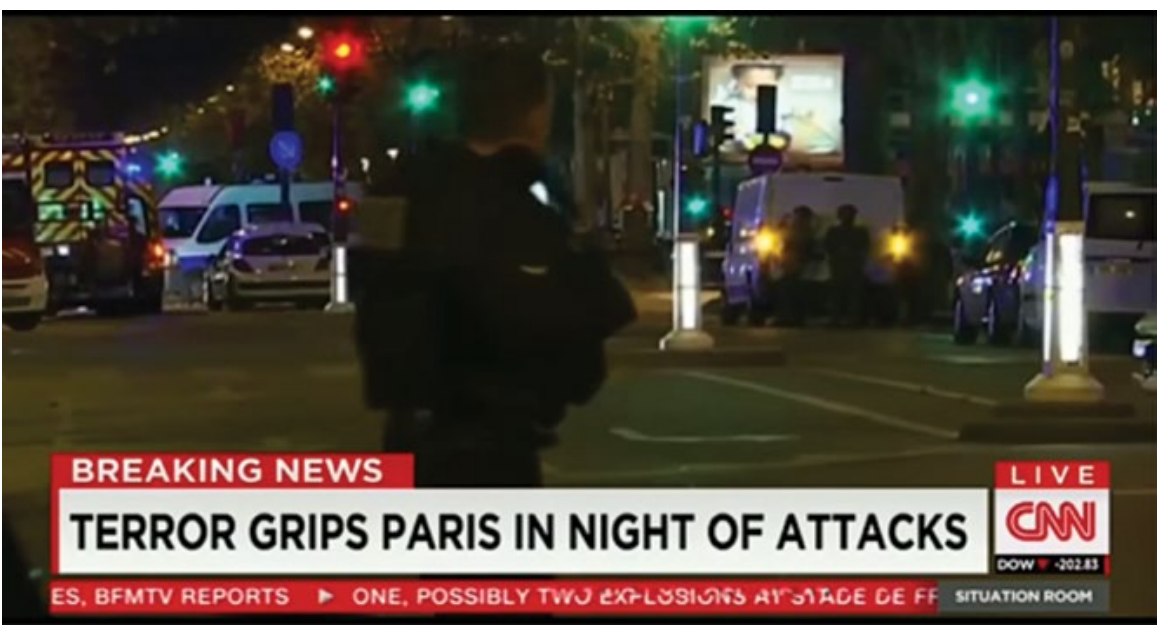

CNN reportando en vivo la acción emergente de los cuerpos de recate tras el atentado. El enunciado dice: "el Terror se toma a París en la noche de los ataques". Fuente: recuperado de YouTube: youtube.com/watch?v=1POFiwWUI8E. 


\section{Imagen 3. Fox News noticiero en vivo tras los atentados en París}

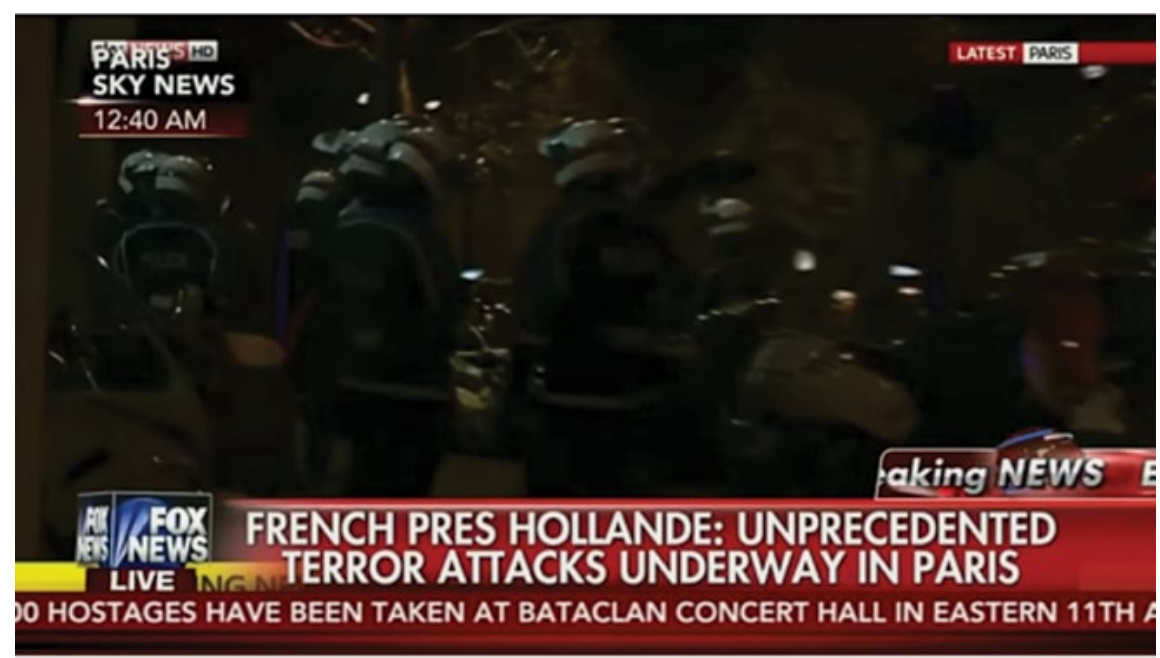

FOX News muestra el incremento de la seguridad en las calles de París tras el atentado. El mensaje dice: "Presidente Francés Hollande: Ataques terroristas sin precedentes se ponen en marcha en París". Fuente: recuperado de YouTube: youtube.com/watch?v=UeaCHfhwHSw

En la imagen (1), el presentador menciona, en el minuto 31:35, las condolencias emitidas por el presidente español Mariano Rajoy a Francia y adherido a eso agrega "que ese dolor ya lo han vivido los españoles y por lo tanto es fácil hacer que se sientan identificados con este mismo dolor”. En la imagen (2), minuto 29:00, uno de los comentaristas del noticiero mencionaba que toda aquella escena en París se había convertido en un verdadero "espectáculo del terror". En la imagen (3), en la hora 3:26 del video, el comentarista menciona que es un acontecimiento histórico.

La dramatización se hace presente en la narración de los comentaristas del noticiero. Catalogar este acontecimiento como un "espectáculo del terror" justifica las acciones militares de los países occidentales en el Medio Oriente, cuestionando si los bombardeos en Siria, Malí o Costa de Marfil no fueran terroríficos para sus habitantes. De igual manera, las palabras de Rajoy mencionadas dentro del análisis político del acontecimiento, también quieren hacer del dolor un proceso espectacular: al emitir imágenes de personas ensangrentadas y en llanto, buscando localizar el dolor en unos ambientes específicos, para hacer identificar a los televidentes bajo el mismo dolor y sufrimiento de los parisinos y no de los sirios, por ejemplo. 
Hay unos localismos y unas guías a partir de los guiones televisivos que destacan qué acontecimientos tienen un derrotero de importancia dentro de la comunicación global y cuáles deben ser evidenciados como simples acciones militares, sin una incidencia mediática de alcance global. Ejemplo de ello, fueron las acciones intervencionistas de Estados Unidos en Afganistan: se mencionan como bajas a efectivos terroristas, las bajas que hicieron los Afganos a Estados Unidos son llamados asesinatos, los conceptos cambian, al igual que el escenario y las imágenes para la exposición del ámbito dramatúrgico de la televisión; los telenoticieros seleccionan las imágenes que han definir la orientación emocional de la noticia.

Lo destacado de las casi 4 horas de emisión de cada uno de los tres noticieros puesto en análisis, es que mencionan conceptos que son pertinentes para el contraste: la identificación con una emoción: el dolor, no como gestión física, sino como sensación. La emisión y el ambiente trasmitido son parte del espectáculo y el valor histórico del acontecimiento como acción significativa para la cultura occidental y sus televidentes. Desde la perspectiva de Bourdieu, la televisión tuvo un monopolio sobre la formación y la información de sus ciudadanos, fueron los productores los que auto-programaron los sucesos y episodios que se presentaron como la única verdad anunciada.

Se consolidó de manera creciente una estética de la transmisión que se basaba en las lógicas de lo espectacular, la dramatización y la estelarización, para despertar la emoción y llegar al mayor público posible (Lipovetsky, 2009). Como sostienen nuevamente Bourdieu:

Nuestros presentadores de telediarios, nuestros moderadores de debates, nuestros comentaristas deportivos, se han convertido, sin tener que esforzarse demasiado, en solapados directores espirituales, portavoces de una moral típica pequeñoburguesa, que dicen «lo que hay que pensar» de lo que ellos llaman «los problemas de la sociedad», la delincuencia en los barrios periféricos o la violencia en la escuela (Bourdieu, 1997, p. 66).

Bourdieu destaca que los telediarios lograron unificar las preocupaciones de los televidentes bajo una misma realidad audiovisual; producir efectos de realidad es la tarea de la televisión, transformar el entorno del televidente a imagen y semejanza de los productores y directores de noticias. La televisión gobernada por los índices de audiencia contribuye a que pesen sobre el consumidor, supuestamente libre e ilustrado, las imposiciones del mercado y de la política, que nada tiene que ver con la expresión democrática de una opinión colectiva ilustrada, 
racional, de una razón publica, como pretenden hacer creer los demagogos cínicos; la televisión reforzó las convenciones sociales de las instituciones políticas (Bourdieu, 1997, p. 96).

Tras la descripción y la interpretación anterior, el análisis de la siguiente parte radica en que la televisión en la era de Internet y especialmente de las redes sociales está obligada a transformarse. Una mirada a la interpretación de los acontecimientos en Francia del 13 de noviembre de 2015 a través de las redes sociales, evidenció que todo el discurso televisivo no logró agrupar las concepciones de todas las personas, como el caso de las páginas de Facebook analizadas: “Colectivo Dignidad” y "Anti-Illuminati 503"; con ello, se abre una perspectiva diferente de los acontecimientos.

\section{Usuarios en Facebook y su percepción de la televisión}

Cuando se habal de usuarios de Facebook, no se hace referencia a la comunidad global que hace parte de esta red social, sino, algunos grupos entre millones que existen en este espacio de internet y que están en contra de los procesos televisivos (así como existen otros grupos que están en contra de otras instituciones sociales y hacen de Internet un espacio para formar su comunidad). Aquí se menciona una página de Facebook que hacen alusión constante a las producciones televisivas y que lleva por nombre "Anti Illuminati 503".

Es pertinente aclarar que con la consolidación del Internet global durante la primera década del siglo XXI y concretamente con la aparición de las redes sociales basadas en Internet, el sujeto pasó de ser un receptor pasivo de información y se está transfigurando en un emisor activo de ellas, se convierte en un informador y en un productor de audiencias, antes que nada y con nuestra evidencia empírica no está demás dejar en claro la cita que Castells (2009) de la USC Center for the Digital Future:

La red ya ha transformado la televisión. Los adolescentes entrevistados por los investigadores, ni siquiera comprenden la idea de ver la televisión con un horario ya programado. Ven programas de televisión en la pantalla del ordenador y, cada vez más, en dispositivos portátiles. Así pues, la televisión sigue siendo un medio de comunicación de masas importante, pero su formato y recepción están cambiando a medida que la recepción se personaliza (p. 100). 
Los sujetos de la sociedad red (Castells, 2001) pueden acceder, cada vez más fácil, a los discursos audiovisuales a través de otros dispositivos y medios en el momento que desean, no cuando la televisión los emite. Esto se debe a que los nuevos medios digitales de Internet son flexibles y capaces de hacer circular en forma pública y privada distintas discursividades (Carlon, 2013), como sostiene Castells (2009):

La World Wide Web es una red de comunicación utilizada para enviar e intercambiar documentos. Estos documentos pueden ser textos, sonidos, vídeos, programas de software, literalmente cualquier cosa que pueda digitalizarse. Por eso carece de sentido comparar Internet con la televisión en términos de audiencia como sucede a menudo con los análisis trasnochados de los medios de comunicación (p. 99).

Los televidentes comienzan a trascender en un proceso más activo de la comunicación. En consecuencia, Carlos Scolari (2008) reconoce los principios para los procesos de digitalización que se basan en hipertextualidad, que tienen la capacidad de dirigirse de uno a muchos y que su interactividad provoca, de manera efectiva, multimedialidad. Todo ello permitió, a través de las redes sociales, construir procesos críticos en contra de la televisión y socializarlos en la red.

Imagen 4. La página Anti Illuminati 503 confronta Internet y la Televisión
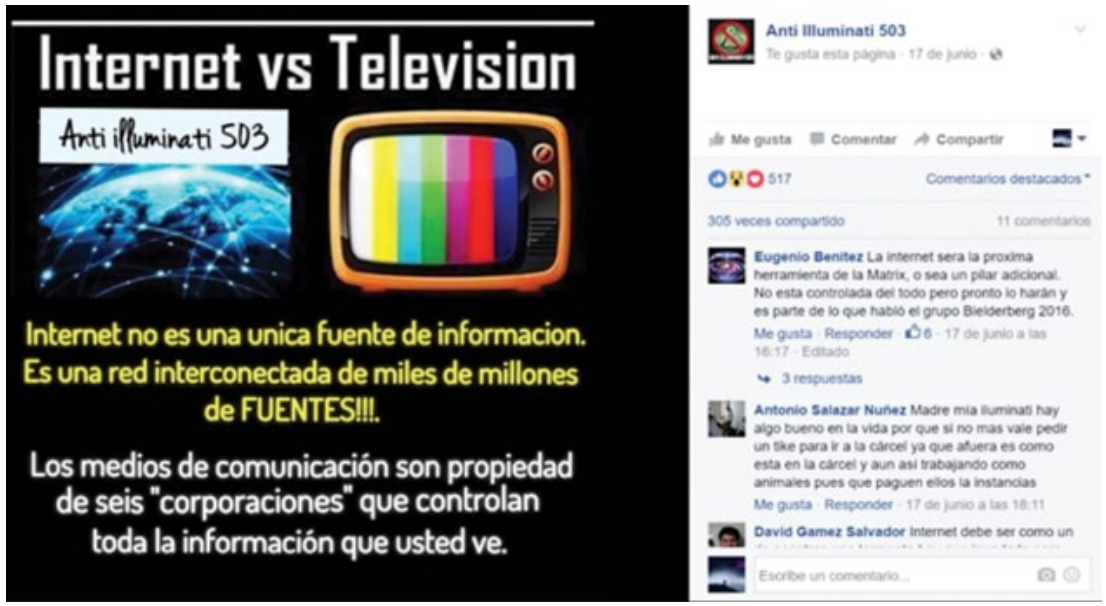

La imagen publicada por la página "Antillluminati 503" confronta a la televisión y al internet con respecto a la libertad de información. Fuente: Recuperado de Facebook: facebook.com/ Antillluminati503/. 
Imagen 5. La página Anti Illuminati 503 menciona la "manipulación” de la televisión.
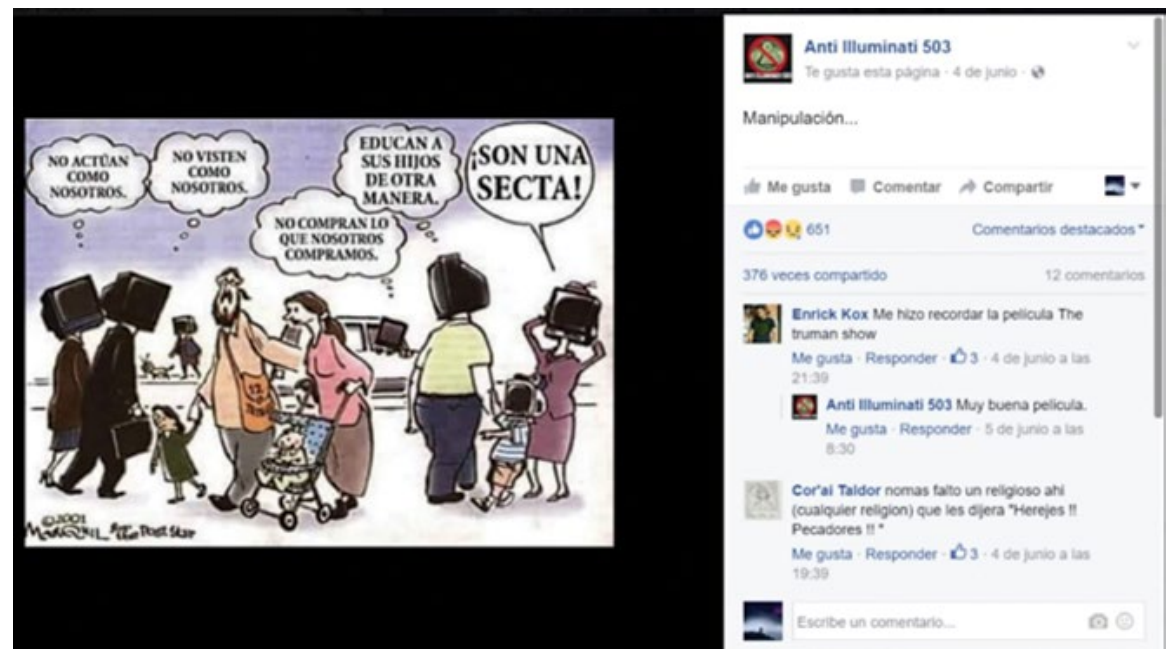

El televisor como representación de la cabeza de los televidentes y fuente del pensamiento manipulado. Fuente: Recuperado de Facebook: facebook.com/Antillluminati503/.

La página de Facebook “Anti Illuminati 503” cuenta con 76.988 seguidores con participación activa en los comentarios. Las publicaciones de esta página develan una posición crítica frente a la televisión y la función que ha tenido en la vida de los seres humanos, la consideran perniciosa y cegada (imagen 5), considerándola una alternativa no viable a la hora de adquirir información (imagen 4). De esta forma, se fortalece la afirmación de Henry Jenkins cuando asegura que "los medias digitales vendrían a «liberarnos » de la «tiranía» de los medios de comunicación de masas" (Jenkins, 2008, p. 243).

Cada uno de los usuarios y su participación en las publicaciones de las imágenes plasma su experiencia personal y sus concepciones personales sobre la televisión, asimilando en cada imagen una situación que resulta negativa a sus circunstancias (Camps, 2011). Las personas encuentran en la red amplias comunidades digitales y la posibilidad de desmitificar las construcciones sociales formadas a través las instituciones tradicionales y las creadas por la televisión; la red se convierte en un sitio de múltiples manifestaciones en contra de la información emitida por los grandes medios y las transmisiones institucionales.

Internet agrupa comunidades en contra y favor de gustos políticos, sociales y culturales; las comunidades no se definen por la cantidad de audiencia o 
seguidores como pasa en la televisión, sino por los usuarios que interactúan en ella, que pueden ser tres o millones de usuarios; las audiencias digitales no son sinónimo de consolidación de transmisión de información, sino de conformación de comunidad que seguirá existiendo con tres usuarios o millones de ellos. Lo importante de la comunidad digital es agrupar a usuarios bajo una idea o una creencia que en la información televisiva puede parecer absurdo o nunca emitida, como sostiene Castells (2009):

Estas comunidades se convierten a menudo en trincheras de resistencia contra el orden social que se considera extraño e impuesto por la fuerza, en un contexto en el que las instituciones que acostumbraban a dar seguridad (el estado, la Iglesia, la familia) dejan de funcionar adecuadamente. Hay por otra parte movimientos sociales que son resultado del cruce de dos pautas culturales: el individualismo en red y el comunalismo (p. 471).

Cada usuario elige lo que coincide con sus convicciones y con los valores que aprecia (Camps, 2011). En estas comunidades digitales "el lenguaje no solo ayuda a organizar el tumultuoso fluir de la propia experiencia y a dar sentido al mundo, sino que también estabiliza el espacio y ordena el tiempo, en diálogo constante con la multitud de otras voces que también nos moldean colorean y rellenan” (Sibilia, 2008, p. 38).

Esas voces múltiples ya tienen voz en red y en tiempo real para decir lo que creen, piensan y sienten sobre acontecimientos como el de París en el 2015; en la red, las personas no asumen en la totalidad la voz de la televisión, sino que establecen posiciones críticas, emotivas y valorativas; esto, gracias a otras fuentes de información alternativa que evidencian otras realidades.

\section{Redes sociales sientan posiciones frente a los atentados en París}

Con lo ocurrido en Francia, Facebook se solidarizó y activó un filtro para que los usuarios pudieran poner en su foto de perfil personal la bandera francesa. El fondo histórico de todo esto es que mucha gente decidió, por cuenta propia, aprovechar la mediatización televisiva para usar la red social Facebook y poner como manifiesto las acciones militares de Francia en otros países. 
Imagen 6. Filtro creado por Facebook para solidarizarse con los atentados en parís.

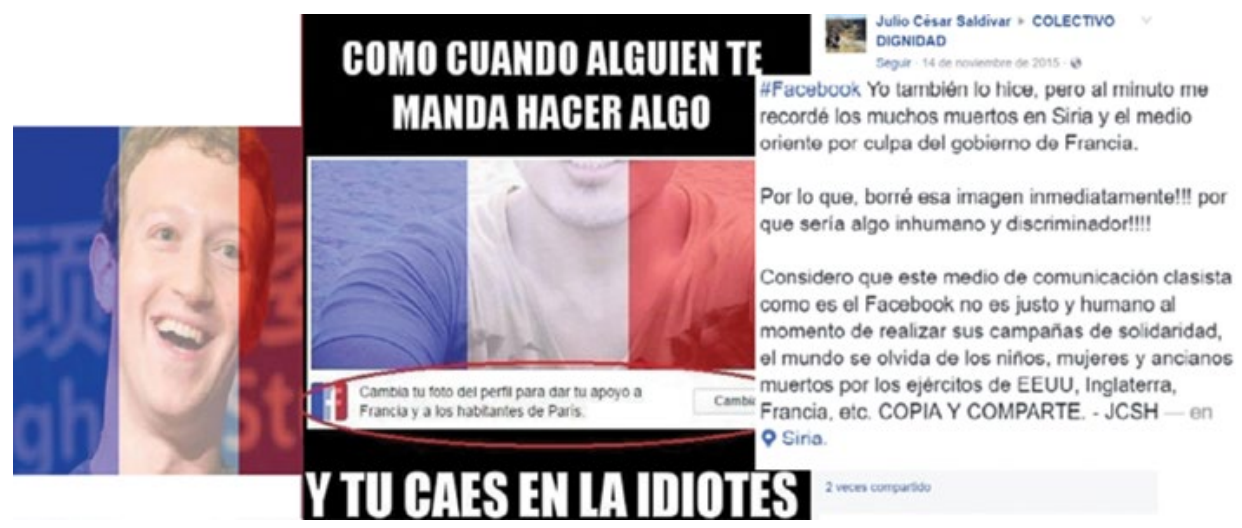

Un usuario en red comenta su postura con respecto al filtro activado por Facebook.

Fuente: Recuperado de Facebook: facebook.com/zuck?fref=ts [(\&)] facebook.com/

COLECTIVODIGNIDAD.ORG/?fref=ts.

Lo que manifiesta el usuario de la imagen 6, que comparte la imagen con el grupo “Colectivo Dignidad”, es su expresión de solidaridad y el sentimiento que le provocan los atentados terroristas en otros países y por los cuales Facebook nunca hace ninguna manifestación pública. Así, los usuarios de estas redes se auto-representan a través de sus convicciones y de sus creencias que se fundamentan en sus conocimientos alternativos de la situación política global y que no viene de una sensibilización política de los principales noticieros, donde "una parte de la acción simbólica de la televisión, a nivel de noticieros, por ejemplo, consiste en llamar la atención sobre unos hechos que por su naturaleza pueden interesar a todo el mundo, de los que cabe decir que son para todos los gustos (...) pero que por su propia naturaleza no toca nada importante” (Bourdieu, 1997, p. 22). 


\section{Imagen 7. Critica a Francia por la invasión a Malí y Costa de Marfil}

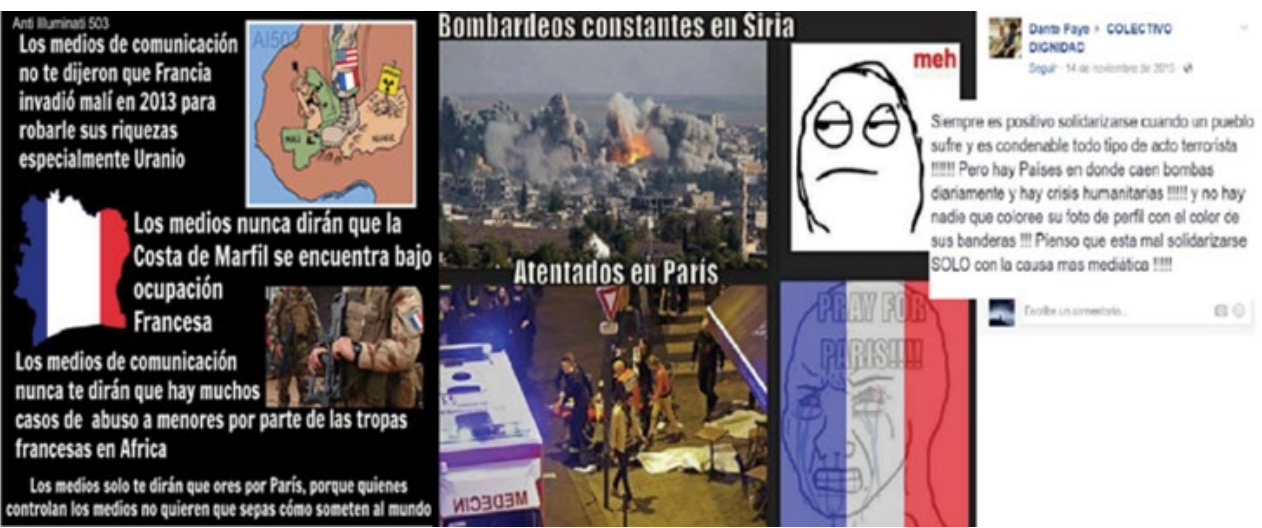

Fuente: Recuperado de Facebook: facebook.com/COLECTIVODIGNIDAD.ORG/?fref=ts (Aunque la primera imagen tiene la referencia "Anti Illuminati 503" la imagen fue tomada de la página "Colectivo Dignidad").

En Facebook, con los acontecimientos en París, se pusieron en evidencia dos momentos: primero, los sujetos que hicieron uso del filtro que Facebook proporcionó y, el segundo, en el que plantaron una posición crítica frente a los exagerados procesos de emisión de los medios televisivos globalmente más reconocidos. Sin embargo, lo destacable de este acontecimiento es que internet y las redes sociales permitieron hacer públicas las emociones, pensamientos y posiciones de los usuarios en red; se visibilizó una múltiple diversificación de expresiones, que permitió a los usuarios estar al descubierto, a la vista de todos y visto por todos, en una búsqueda afanosa de pruebas de reconocimiento social: hoy "la privacidad [individual] invadió, conquistó y colonizó el ámbito público pero a costa de perder su derecho al secreto que es su característica definitoria y su privilegio más querido y ferozmente defendido” (Bauman y Lyon, 2013, p. 36). Y al decir de Castells (2009),

Las redes de comunicación horizontal basadas en Internet se activan gracias a sujetos comunicativos que determinan tanto el contenido como el destino del mensaje y son al mismo tiempo emisores y receptores de flujos de mensajes multidireccionales" (p. 181)

Los usos de estas páginas de redes sociales son estrategias que los sujetos ponen en acción para responder a nuevas demandas socioculturales, señalando 
nuevas formas de ser y de estar en el mundo (Sibilia, 2008, p. 28). La televisión, por sus características técnicas, no pudo evidentemente, ser un medio inclusivo y activamente participativo. Esto, porque no permite una expansión en la que las personas desarrollen sus propios sistemas de expresión y comunicación; al contrario de Internet.

El ciberespacio [es] una pura simulación, los deseos pueden ser todo lo extravagantes y transgresores que se quiera, ya que, puesto que no tienen consecuencias materiales, todo está permitido en él. Incluso las llamadas perversiones o parafilias, en su amplia gama de modalidades. Y los deseos pueden ser también transferidos a objetos virtuales, como hacen los usuarios de las grandes muñecas hinchables para satisfacer los impulsos de su libido (Gubern, 2007, p. 210).

Como lo expresa Gubern (2007), Internet es un espacio esencialmente de proyección relacionada con las emociones y los deseos, donde hay encuentro de personas que coinciden con la misma percepción de realidad, con miradas múltiples y variadas; la característica fundamental de la red, es la conexión y la participación activa.

Como se observó en una de las imágenes de Facebook sobre París (imagen 7), no todas las personas tienen una relación directa con las interpretaciones de la televisión, sino que la prohíben y la censuran a la hora de adquirir información. El grupo "Colectivo de Dignidad" y sus participantes, demostraron que la indignación y cualquier otra emoción son el origen para conectarse con redes que permitan intercambiar información voluntariamente y formar comunidad; esto permite defender un mensaje común que comparten rasgos afines, ya que

(...) las redes resultan sumamente valiosas en lo que se refiere a estas cuestiones, como espacio para la negociación de significados. El aprendizaje político que tiene lugar dentro de las redes abarca no sólo estrategias y tácticas, sino también cambios normativos en la interpretación de las identidades y responsabilidades compartidas (Keck y Sikkink, 1998, p. 410).

Estas páginas analizadas "Anti Illuminati 503” y “Colectivo Dignidad” permiten que los espacios en Internet tengan sentido: tienen una carga simbólica de 
intercambio de información y, al mismo tiempo, los actores sociales y ciudadanos están usando esta nueva capacidad de las redes de comunicación para avanzar con sus proyectos, defender sus intereses y reafirmar sus valores. Así, "El nuevo campo de comunicación de nuestra época está surgiendo a través de un proceso de cambio multidimensional configurado por los conflictos enraizados en la estructura contradictoria de intereses y valores que constituyen la sociedad" (Castells, 2009, p. 91).

En el ámbito de los acontecimientos políticos como el sucedido en Francia, Internet se convirtió en un lugar donde los actores políticos informales pueden hacer política a través de sus críticas en imágenes y mensajes, algo que resultaría mucho más dificultoso si quisieran hacerlo a través del sistema político tradicional (Keck y Sikkink, 1998). De este modo, "la red mundial de computadoras se ha convertido en un gran laboratorio, un terreno propicio para experimentar y diseñar nuevas subjetividades: en sus meandros nacen formas novedosas de ser y estar en el mundo” (Sibilia, 2008, p. 34).

Lo que evidenció el grupo “Colectivo Dignidad” en contra de la masificación televisiva tras los acontecimientos en París y las imágenes del perfil "Anti-Illuminati 503" en contra de la televisión como medio que se atribuye una única vedad, es el establecimiento de valores y discursos comunes que sobrellevan procesos densos de información y conexión. Por tanto, las transformaciones recíprocas de las preferencias e identidades de los actores que participan son el resultado de sus interacciones, debido a que las redes son voluntarias y horizontales, los actores que participan en ellas obtienen conocimientos y beneficios, las redes no son correas de transmisión de los ideales institucionales tradicionales, sino vehículos para el intercambio comunicativo, con capacidad para transformar a los participantes (Keck y Sikkink, 1998).

Lo anterior es el recurso para que las redes sociales sean la herramienta decisiva para movilizar, organizar, deliberar coordinar y decidir (Castells, 2012). Las redes permiten, de igual manera, un proceso de auto-representación a través de imágenes compartidas en estos perfiles de Facebook como los usuarios que compartieron información reflexiva sobre los acontecimientos en París. A esto se suman otras formas expresivas como fotografías y videos; de este modo, el usuario ya no decide entre canal [A] o canal [B]: elige entre miles de videos y páginas Web con contenido específico y de su interés personalizado. 


\section{Conclusiones}

Con las redes sociales en Internet están cambiando todos los modelos de comunicación política. Los medios antecesores se están transformando en los procesos de guiones y en tecnológicos. Hoy, la televisión está en el proceso de digitalización y conexión a Internet permitiendo una interconexión entre medios; la única variación termina siendo el tamaño del dispositivo.

En la última década de este siglo, se amplió el catálogo de medios cuyo dispositivos ya no son de uso familiar, sino estrictamente personal: computadoras, reproductores MP5, notebooks, tablets, teléfonos celulares (Sibilia, 2008), que permiten un desarrollo expresivo más íntimo y personalizado del sujeto que los usa.

Internet es múltiple e impredecible; es inmensa la información contenida en la totalidad de la red. Ello, no quiere decir que la televisión sea remplazada, pues sigue teniendo altas audiencias, pero ya no es el único medio audiovisual que suministra información de carácter global.

Hoy en día un video o una imagen en Facebook puede hacerse global en cuestión de horas, mientras que las emisiones televisivas de los noticieros tienen que esperar el horario de emisión de la noticia para acceder a la información. Facebook, por ejemplo, adelanta a través de páginas y perfiles información variada y múltiple sobre acontecimientos de interés para el usuario que habita la red y que no es mencionado por ningún noticiero ni programa de televisión.

Con el análisis del caso de Francia se demostró que no todos los sujetos son receptores pasivos de la información emitida, sino que aprovechan estas redes sociales para participar e interactuar sobre la forma del mensaje emitido por la telenoticia.

En el telenoticiero, se expone el mensaje en un tono dramático pero en el fondo no siempre toca fondo de lo importante; generaliza el acontecimiento y lo subsume en un mismo aspecto emotivo para dar dirección a los valores de los televidentes.

En relación con la estructura de las redes sociales, es posible afirmar que su finalidad, por ejemplo Facebook, es disponer las condiciones para que los usuarios establezcan contactos, restablezcan con los contactos del pasado, interactúen e intercambien. En otros términos, lo que hacen las redes sociales es activar las relaciones a través de un sistema basado en la expresión de la identidad de 
los usuarios, dispone aplicaciones para hacer (incitar), expresar o exhibir gustos, preferencias, ideologías, hobbies, etc. (Acosta y Maya, 2012, p. 53).

Los usuarios en sus redes de conexión buscan formas de conocer y agrupar sus inquietudes, gustos, miedos, creencias y todo tipo de pensamiento y sentimiento individual que lo lleven a encontrar en la red una comunidad con las mismas características. Por tanto, la participación ya no se reduce al consumo intacto de información, sino que su participación activa es lo que permite formular la comunidad en red. Al respecto, Castell (2009), afirma que

Las redes de asociaciones de imágenes, ideas y sentimientos que se conectan con el tiempo constituyen patrones neuronales que estructuran las emociones, los sentimientos y la conciencia. Así pues, la mente funciona conectando en red modelos cerebrales con modelos de percepción sensorial que derivan del contacto con las redes de materia, energía y actividad que constituyen nuestra experiencia, pasada, presente y futura (anticipando las consecuencias de cierras señales de acuerdo con las imágenes almacenadas en el cerebro). Somos redes conectadas a un mundo de redes (p. 193).

Los sujetos encuentran en la red múltiples posibilidades de unión y participación; en caso de no encontrar ninguna, las redes sociales permiten crear grupos, páginas, blogs, entre otros espacios de participación activa abiertas a que otros usuarios con las mismas inquietudes y creencias participen.

La red permitió la expresión de diferentes realidades subjetivas, también abrió paso a la formación de comunidades, culturas y prácticas no convencionales, donde la fuerza invasora de cada usuario permite expresar lo que cree y lo que piensa tomando el espacio sin adueñarse de él (Rosanvallon, 2007).

Finalmente, el medio no constituye el mensaje; el medio se construye por la multiplicidad de interacciones y creaciones de los sujetos en red que se liberan de la represión del espacio físico y controlado, hibridan las estructuras sociales impuestas y mediatizadas por la televisión y se geneera un nuevo ensamblaje y práctica cultural de su ambiente y de su conexión global con estructuras similares (Sassen, 2010). 


\section{Referencias}

Acosta, G., y Maya, C. (2012). Participación política en redes sociales: el caso de los grupos en Facebook. Medellín, Colombia: Sello Editorial Universidad de Medellín.

Ardevol, E., y San Cornelio, G. (2007- N 7). Si quieres vernos en acción: YouTube.com. Prácticas mediáticas y autoproclamación en Internet. Revista Chilena de Antropología Visual, 1-29.

Bauman, Z. (2008). Miedo líquido. Buenos Aires, Argentina: Paidos.

Bauman, Z., y Lyon, D. (2013). Vigilancia líquida. Buenos Aires, Argentina: Paidos.

British Broadcasting Corporation, BBC. (2015). Francia: lo que se sabe de los ataques reivindicados por Estado Islámico que dejaron al menos 132 muertos en París enlace: www.bbc.com/mundo/noticias/2015/11/151113_paris_ataque_ep

Bergman, M. (2001). White Paper: The Deep Web: Surfacing Hidden Value. The Journal of Electronic Publishing. Recuperado de: http://quod. lib.umich.edu/cgi/t/text/idx/j/jep/3336451.0007.104/--white-paper-the-deep-web-surfacing-hidden-value?rgn=main;view=fulltext

Bourdieu, P. (1997). Sobre la televisión. Barcelona, España: Anagrama.

Camps, V. (2011). El gobierno de las emociones. Barcelona, España: Herder .

Carlon, M. (2013). Televisión y masas. De la representación histórica a la nueva etapa de mediatización. En M. Mestman. Masa, pueblo, multitud en cine y televisión (págs. 69-89). Buenos Aires, Argentina: Editorial Universidad de Buenos Aires.

Castells, M. (2001). La era de la información Vol. II. Mexico : Siglo Veintiuno.

Castells, M. (2009). Comunicación y poder. Madrid, España: Alianza Editorial.

Castells, M. (2012). Redes de indignación y esperanza. Madrid, España: Alianza Editorial. 
Cicco, J. D. (2008). Toutube: El archivo audiovisual de la memoria colectiva. Recuperado de: http://www.palermo.edu/ingenieria/downloads/pdfwebc\&T8/ 8CyTo6.pdf

Gubern, R. (2007). El eros electrónico. Mexico: Tauros.

Jenkins, H. (2008). Convengersce Culture. Barcelona, España: Paidos

Keck, M. y Sikkink, K. (1998). Redes transnacionales de cabildeo e influencia. Ithaca, Nueva York: Cornell University Press.

Lipovetsky, G. y Serroy, J. (2009). La pantalla global. Barcelona, España: Anagrama.

McLuhan, M. y Powers, B. (1995). La aldea global. Barcelona, España: Gedisa.

Página Anti Iluminati (2015). Facebook: Anti Illumitati 503. Enlace: facebook. com/Antillluminati503/

Página Colectivo Dignidad (2015). Facebook: Colectivo Dignidad. Enlace: Facebook.com/COLECTIVODIGNIDAD.ORG/?fref =ts

Rosanvallon, P. (2008). La contrademocracia. Buenos Aires, Argentina: Manantial.

Sartori, G. (1997). Homo videns. Madrid, España: Tauros.

Sassen, S. (2010). Territorio, autoridad y derecho. Buenos Aires, Argentina: Katz.

Sibilia, P. (2008). La intimidad como espectáculo. Buenos Aires, Argentina: Fondo de Cultura Económica.

YouTube: Emisión de los atentados en Paris, CNN: Enlace: youtube.com/watch?v=1PoFiwWUl8E

YouTube: Emisión de los atentados en Paris, Canal 13 Televisión: Enlace: youtube.com/watch?v=pmj5VdeLSZA

YouTube: Emisión de los atentados en Paris, Fox News: Enlace: youtube.com/ watch? $\mathrm{v}=\mathrm{UeaCH}$ hw HSw 